\title{
VLSI Design Special Issue on Semiconductor Device Modeling
}

\author{
CARL L. GARDNER*
}

Department of Mathematics, Arizona State University, Tempe, AZ 85287-1804, USA

(Received 1 May 2001; Revised 1 April 2002)

\section{INTRODUCTION}

This issue of VLSI Design is devoted to modeling and simulation of ultra-small scale classical and quantum effects in state-of-the-art semiconductor devices. The articles gathered here present simulations of a wide variety of contemporary semiconductor devices using both classical and quantum transport models; mathematical analysis of charge transport; and numerical methods that span the spectrum from modern hyperbolic finite difference methods for the hydrodynamic model to Monte Carlo methods for the Boltzmann transport equation. Semiconductor device modeling — as these articles demonstratecontinues to involve a broad range of interdisciplinary approaches combining electrical engineering, applied mathematics, numerical analysis, and device physics.

*Corresponding author. Tel.: +1-480-965-0226. Fax: +1-480-965-0461. E-mail: gardner@asu.edu 

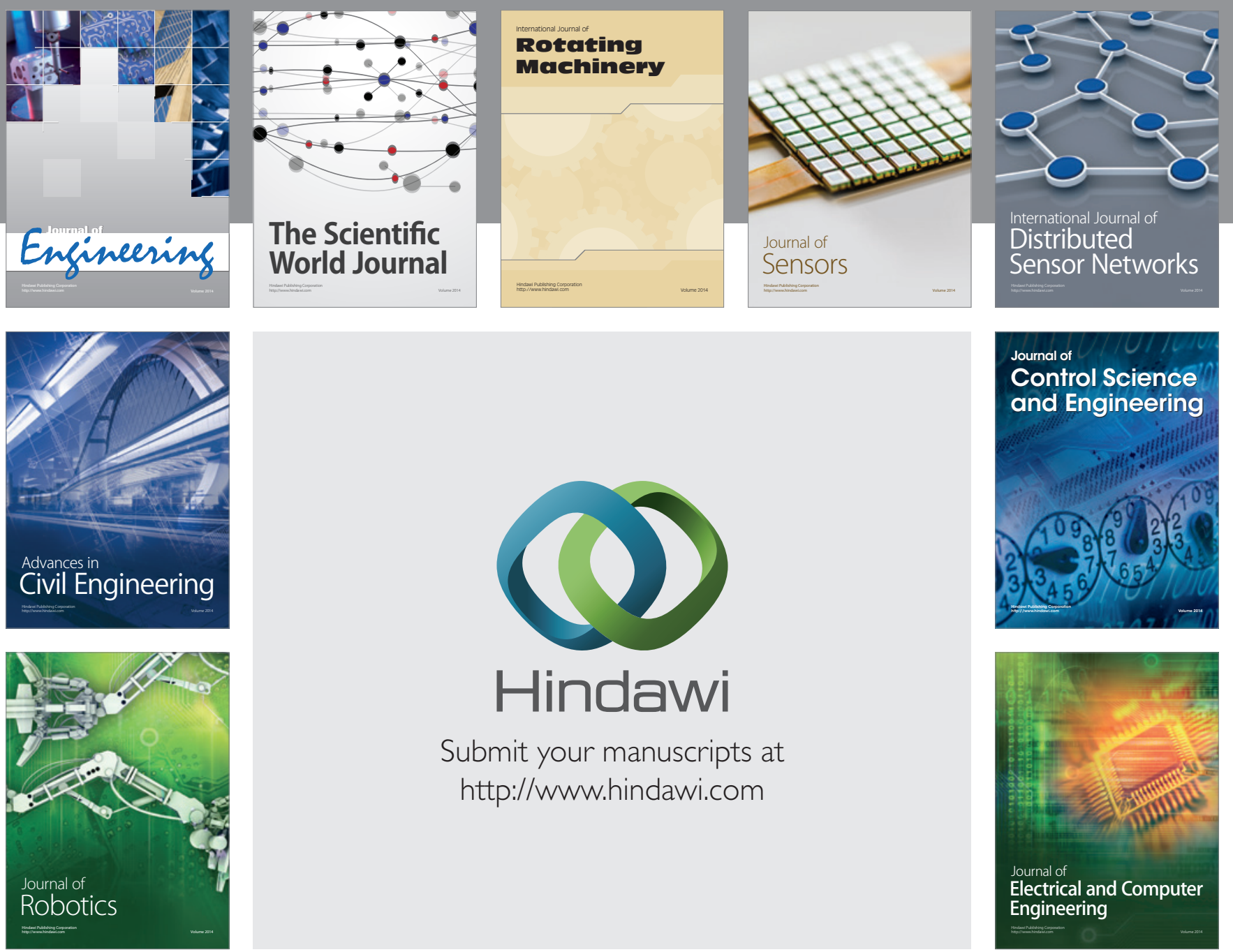

Submit your manuscripts at

http://www.hindawi.com
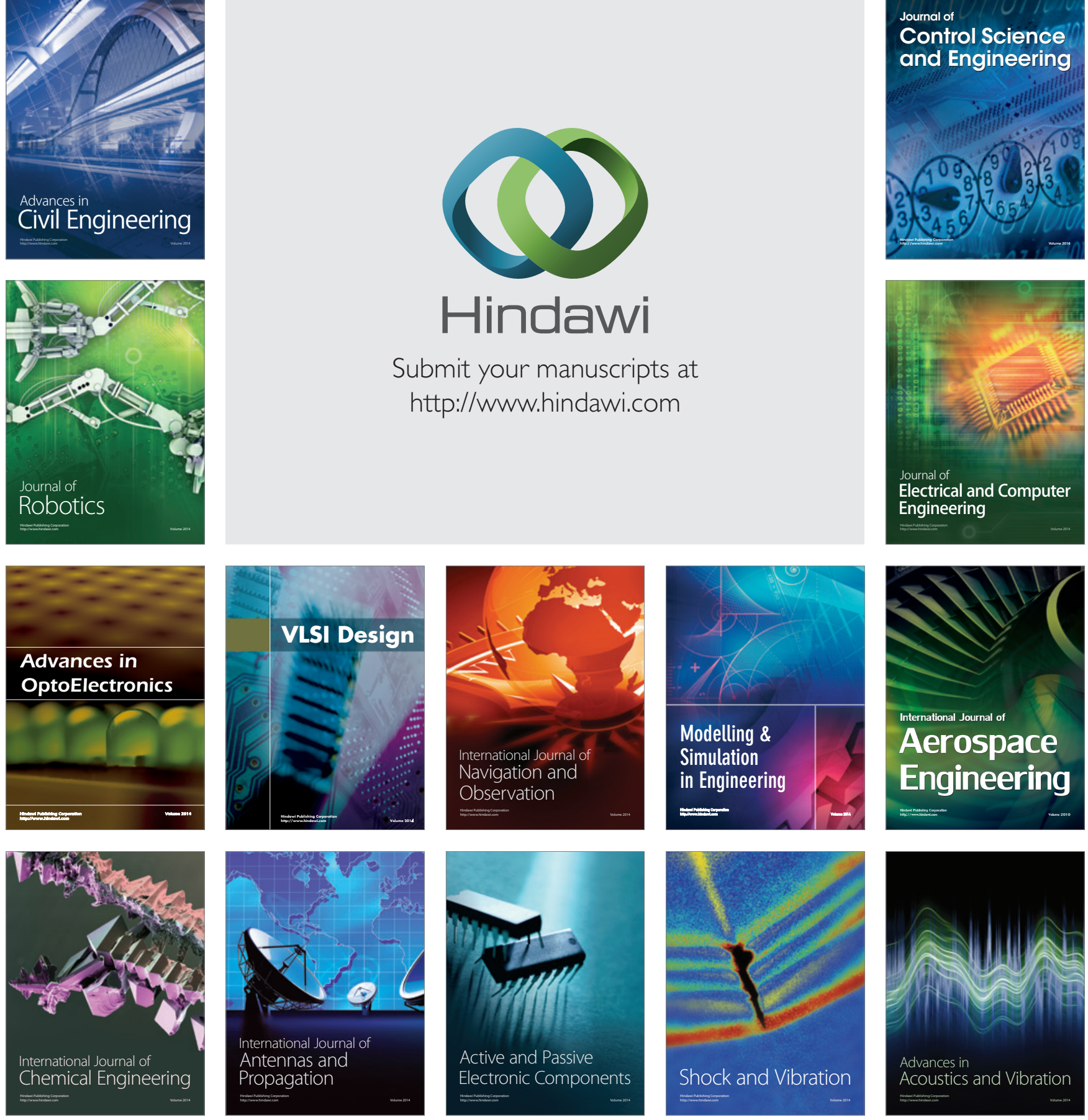